\title{
The antibacterial arm of the Drosophila innate immune response requires an IкB kinase
}

\author{
Yiran Lu, ${ }^{1,2}$ Louisa P. Wu, ${ }^{1,3}$ and Kathryn V. Anderson ${ }^{1,2,4}$ \\ ${ }^{1}$ Molecular Biology Program, Sloan-Kettering Institute, New York, New York 10021, USA; ${ }^{2}$ Molecular and Cell Biology \\ Program, Cornell University, Weill Graduate School of Medical Sciences, New York, New York 10021, USA
}

The ird5 gene was identified in a genetic screen for Drosophila immune response mutants. Mutations in ird5 prevent induction of six antibacterial peptide genes in response to infection but do not affect the induction of an antifungal peptide gene. Consistent with this finding, Escherichia coli survive 100 times better in ird5 adults than in wild-type animals. The ird5 gene encodes a Drosophila homolog of mammalian IkB kinases (IKKs). The ird5 phenotype and sequence suggest that the gene is specifically required for the activation of Relish, a Drosophila NF-кB family member.

[Key Words: Innate immunity; IкB kinase; Drosophila; antimicrobial peptide; Relish; NF-кB]

Received May 2, 2000; revised version accepted November 15, 2000.

In both mammals and Drosophila, microbial infection activates Toll-like receptor (TLR) signaling pathways as a part of the innate host defense response (for review, see Anderson 2000). TLR-mediated signaling pathways are essential for appropriate responses to bacterial infection. In addition, mouse Tlr4 mediates septic shock associated with infection by gram-negative bacteria (Vogel 1992; Poltorak et al. 1998).

The available data indicate that different microbial cell wall components activate different Toll-like receptor signaling pathways, which regulate distinct sets of target genes. In mammals, TLR4 is the prime mediator of responses to bacterial lipopolysaccharide, while TLR2 mediates responses to bacterial peptidoglycans (Poltorak et al. 1998; Takeuchi et al. 1999; for review, see Beutler 2000). The best-studied aspect of the Drosophila innate immune response is the rapid transcriptional induction of antimicrobial peptide genes in response to infection (Hultmark 1993; Hoffmann 1995). Infection by different classes of microorganisms leads to the preferential induction of particular subsets of antimicrobial peptides (Lemaitre et al. 1997), indicating that different microbial components activate different signaling pathways.

At least two Toll-related signaling pathways are required for the activation of the Drosophila antimicrobial peptide genes. The Toll pathway itself, which was first identified because of its essential role in Drosophila embryonic patterning (Anderson et al. 1985), is essential for

\footnotetext{
${ }^{3}$ Present address: Center for Agricultural Biotechnology, University of Maryland Biotechnology Institute, College Park, MD 20742, USA. ${ }^{4}$ Corresponding author.

E-MAIL k-anderson@ski.mskcc.org; FAX (212) 717-3623.

Article and publication are at www.genesdev.org/cgi/doi/10.1101/ gad.856901.
}

the induction of an antifungal peptide gene, drosomycin, although the antibacterial peptide genes are still induced in Toll pathway mutants (Lemaitre et al. 1996). Another Drosophila member of the Toll family, 18-wheeler, is required for the normal induction of attacin, an antibacterial peptide gene, but mutations in 18-wheeler do not prevent the induction of other antibacterial peptides (Williams et al. 1997). The imd gene is important for the induction of Diptericin and other antibacterial peptides (Lemaitre et al. 1995a; Corbo and Levine 1996) and, therefore, appears to be a component of a third signaling pathway activated by infection, but its biochemical function is not known.

Each of the three Drosophila signaling pathways activated by infection leads to activation of NF-kB/Rel dimers, just as the mammalian TLRs activate NF-кB. All three Drosophila Rel proteins, Dorsal, Dif, and Relish, are expressed in the fat body cells that produce the antimicrobial peptides, and all three are activated within 30 min after infection by translocation from the cytoplasm to the nuclei (Ip at al. 1993; Lemaitre et al. 1995b; Stöven et al. 2000). Adults that lack Dif fail to induce Drosomycin, an antifungal peptide, and Defensin, which is active against gram-positive bacteria, but the other antimicrobial peptide genes are induced normally (Manfruelli et al. 1999; Meng et al. 1999; Rutschmann et al. 2000). Animals that lack Dorsal show normal induction of the antimicrobial peptide genes in response to infection (Lemaitre et al. 1995b), although Dorsal may act redundantly with Dif in larvae (Manfruelli et al. 1999; Rutschmann et al. 2000). Relish is a compound protein with an N-terminal Rel domain and a C-terminal IкBlike domain, similar to mammalian p100 and p105 (Dushay et al. 1996). Relish is activated by signal-depen- 
dent proteolysis, which liberates the N-terminal Rel domain, allowing it to translocate into nuclei (Stöven et al. 2000). Adults that lack Relish completely fail to induce the antibacterial peptides Diptericin and Cecropin and show reduced induction of the other antimicrobial peptides (Hedengren et al. 1999).

The signaling pathway that activates Relish and controls induction of the antibacterial peptide genes has not been defined. We carried out a genetic screen to identify EMS-induced mutations on the Drosophila third chromosome that affect the antibacterial signaling pathway (Wu and Anderson 1998). A large number of mutants were identified and named ird (immune response deficient) mutants. This screen identified two alleles of the ird5 gene on the basis of the failure of homozygous mutant larvae to induce a diptericin-lacZ reporter gene in response to infection. Here we show that the ird5 gene is essential for antibacterial responses and encodes a Drosophila homolog of mammalian ІкB kinases.

\section{Results and Discussion}

ird5 mutations block the antibacterial but not the antifungal immune response

Mutations in ird5 prevent induction of a diptericin-lacZ reporter gene in response to infection and also prevent transcriptional induction of the endogenous diptericin gene (Wu and Anderson 1998). We examined E. coli-induced expression of all seven classes of antimicrobial peptide genes in ird5 mutant larvae by RNA blot hybridization, including the genes encoding antibacterial (Diptericin, Cecropin A, Defensin, Attacin, Drosocin, and Metchnikowin) and antifungal (Drosomycin) peptides (Fig. 1A,B). In wild-type larvae, all the antimicrobial genes were strongly induced after bacterial challenge. In contrast, in larvae homozygous for either ird5 allele, there was no detectable induction of the diptericin, cecropin $A$, defensin, drosocin, or metchnikowin genes. The attacin gene was induced in the mutants to $\sim 30 \%$ of normal levels, while drosomycin was induced to normal levels (Fig. 1; Table 1). The same effects on the induction of antimicrobial peptide genes were seen in $\operatorname{ird} 5^{1} / D f$ and

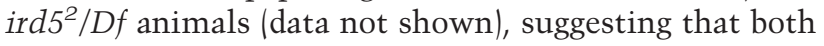
alleles cause a complete loss of gene function.

Mutations in three other genes, imd, Relish, and Dredd, have been shown to prevent normal induction of antibacterial peptide genes in adult Drosophila (Hedengren et al. 1999; Elrod-Erickson et al. 2000; Leulier et al. 2000). We compared the pattern of antimicrobial peptide gene induction in ird5 mutants with that in imd and Relish mutants in both larvae and adults (Fig. 1A; Table 1). Mutations in all three genes had very similar effects on antimicrobial gene induction in larvae: diptericin and cecropin A were not induced; attacin induction was reduced and drosomycin induction was normal. In adult animals, the antimicrobial gene expression phenotype of ird5 and Relish mutants were very similar: diptericin induction was blocked, cecropin $A$ and attacin induction was reduced, and drosomycin induction was normal. The antimicrobial gene expression phenotype of imd adults was slightly different, with some residual diptericin expression. Mutations in Dredd, a Drosophila caspase, prevent normal induction of diptericin and attacin and allow induction of drosomycin (Elrod-Erickson et al. 2000; Leulier et al. 2000). These comparisons suggest that ird5, Dredd, Relish, and probably imd act in the same signaling pathway to control the induction of antibacterial peptide genes in response to infection.

To assess the importance of the ird5 gene in controlling the growth of invading bacteria, we compared bacterial survival and growth in wild-type, ird5, imd, and Relish animals (see Materials and Methods). In wild-type larvae, most of the E. coli injected into the animal were killed by $6 \mathrm{~h}$ after infection (Fig. 2A). At this same time point, there were four to 15 times as many E. coli in ird5 mutant larvae as in wild-type animals (Fig. 2B). The effects of the ird5 mutations were more striking in experiments with adults: at $24 \mathrm{~h}$ after infection, there were 20-350 times as many bacteria per animal in ird5 mutants compared to wild type. The bacterial growth phenotype of ird5 mutants was similar to that seen in Relish
A

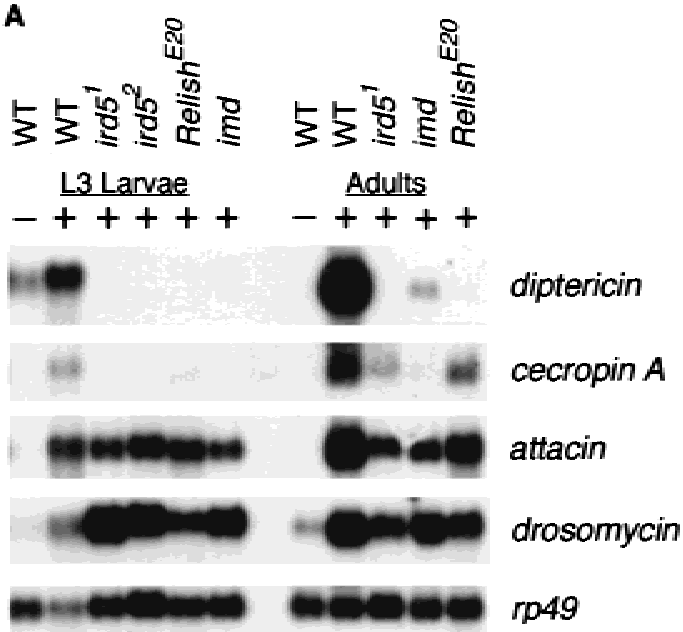

B

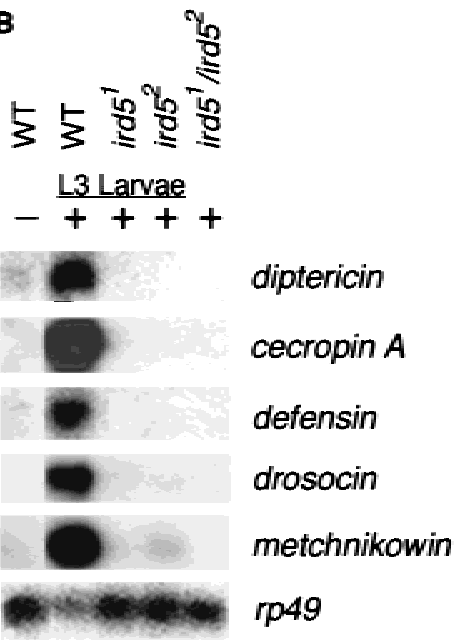

Figure 1. Expression of the antimicrobial peptide genes in wild-type and mutant animals. The induction of antimicrobial peptide genes was assayed by Northern blot. (A) Induction of diptericin, cecropin, drosomycin, and attacin in wild-type, ird5, Relish, and imd mutants in response to infection at L3 larval and adult stages. $(B)$ Induction of the battery of antimicrobial peptides in wild-type and ird5 mutants at L3 larval stage. Each lane contains $30 \mu \mathrm{g}$ of total RNA from untreated third-instar larvae (-) or 2-3 h after injection with Escherichia coli $(+)$. rp49 was used as loading control. 
Lu et al.

Table 1. Induction of antimicrobial peptides in mutants

\begin{tabular}{|c|c|c|c|c|c|c|c|c|c|c|c|}
\hline \multirow{3}{*}{$\begin{array}{l}\text { Antimicrobial } \\
\text { peptides }\end{array}$} & \multicolumn{6}{|c|}{ L3 Larvae } & \multicolumn{5}{|c|}{ Adults } \\
\hline & Wild type & Wild type & $\operatorname{ird} 5^{1}$ & $\operatorname{ird} 5^{2}$ & Relish & imd & Wild type & Wild type & $\operatorname{ird} 5^{1}$ & Relish & imd \\
\hline & Uninfected & \multicolumn{5}{|c|}{ Infected } & Uninfected & \multicolumn{4}{|c|}{ Infected } \\
\hline diptericin & 0 & 100 & $0 \pm 0$ & $0 \pm 0$ & $0 \pm 0$ & $0 \pm 2$ & 0 & 100 & $1 \pm 1$ & $0 \pm 0$ & $13 \pm 7$ \\
\hline cecropin & 0 & 100 & $0 \pm 0$ & $0 \pm 0$ & $0 \pm 0$ & $0 \pm 0$ & 0 & 100 & $14 \pm 2$ & $30 \pm 7$ & $5 \pm 3$ \\
\hline attacin & 0 & 100 & $33 \pm 20$ & $29 \pm 16$ & $43 \pm 28$ & $20 \pm 15$ & 0 & 100 & $35 \pm 17$ & $64 \pm 30$ & $47 \pm 26$ \\
\hline drosomycin & 0 & 100 & $125 \pm 21$ & $54 \pm 39$ & $46 \pm 28$ & $76 \pm 30$ & 0 & 100 & $40 \pm 15$ & $71 \pm 18$ & $90 \pm 8$ \\
\hline
\end{tabular}

Induction of antimicrobial peptides in response to infection in mutant animals, expressed as the percentage of the induction seen in wild type. Northern blots (including the data in Fig. 1) were analyzed by phosphorimager and normalized relative to the $r p 49$ loading control. The average and standard deviation in three experiments are shown.

mutant larvae and adults and somewhat stronger than that of imd mutants (Fig. 2B). This is consistent with the stronger effects of ird5 and Relish on the antimicrobial peptide genes: Mutations in either ird5 or Relish prevent normal induction of diptericin, cecropin, drosocin, attacin, and metchnikowin (Fig. 1; Hedengren et al. 1999), while induction of metchnikowin is induced in imd mutants (Levashina et al. 1998).

\section{ird5 encodes a Drosophila $І \kappa B$ kinase}

We mapped the mutations responsible for the failure to induce the diptericin-lac $Z$ reporter gene for both ird5 alleles between the visible markers cu (86D1-4) and $s r$ (90D2-F7) on the right arm of the third chromosome. The deficiency $\mathrm{Df}(3 \mathrm{R}) s b d^{45}(89 \mathrm{~B} 4-10)$ failed to complement the immune response defect of either ird5 allele. Further deficiency-complementation tests and male recombination mapping narrowed the ird5 interval to 89B4-9, between pannier and Stubble (data not shown). Two molecular-defined genes in this interval were considered as candidates responsible for the ird5 phenotype, Akt and a gene defined by an EST that was related to mammalian IкB kinases (IKKs; Fig. 3A). Mutant alleles of Akt cause recessive lethality (Staveley et al. 1998), and ird5/ Akt(1(3)89Bq) heterozygous animals were viable and showed normal induction of the diptericin-lacZ reporter gene (data not shown), indicating that the ird5 phenotypes were not caused by mutations in Akt.

Mammalian IKK $\beta$ is required for activation of NF-кB
A

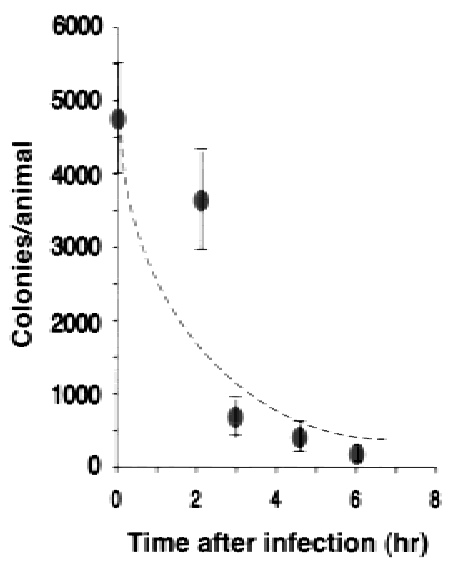

B

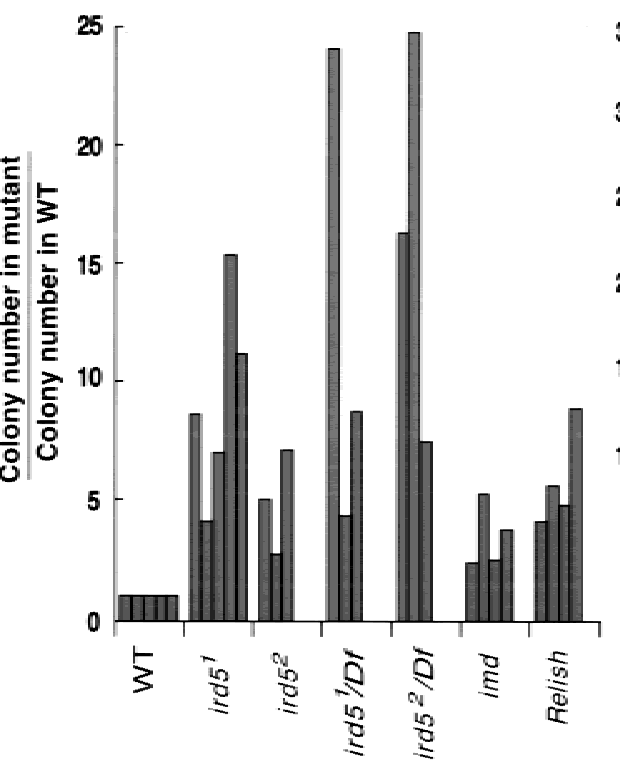

Adults

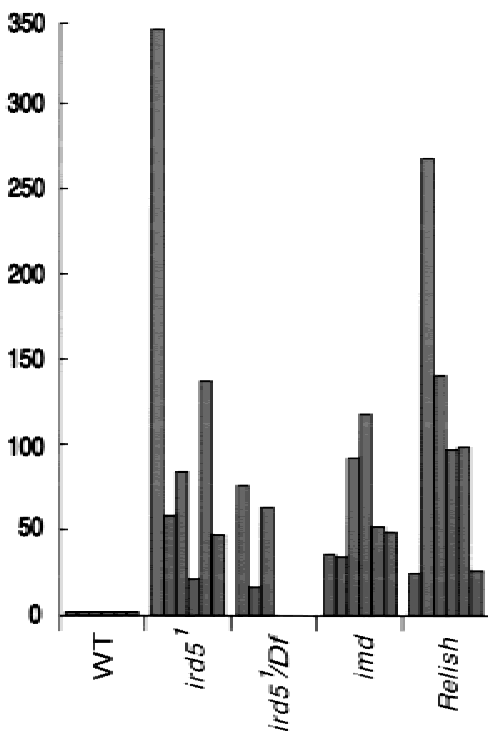

Figure 2. Analysis of bacterial growth after Escherichia coli infection. (A) Wild-type larvae kill E. coli within hours after infection. The number of ampicillin-resistant $E$. coli present per animal at time points after injection is shown. The data shown are the average of two experiments, with three to five animals per time point in each experiment. $(B)$ Bacterial growth in wild-type, ird5, Relish, and imd mutant larvae and adults after infection, indicated as the ratio of the number of colony-forming units (cfu) per animal in the mutant relative to the number of cfu in the wild-type control in the same experiment. Each bar represents an independent experiment. For larvae, the number of bacteria per animal was assayed at $6 \mathrm{~h}$ after infection to ensure that the animals had not begun to pupate. For adults, the number of bacteria per animal was assayed at $24 \mathrm{~h}$ after infection. Df: Df(3R)sbd $d^{45}$. 


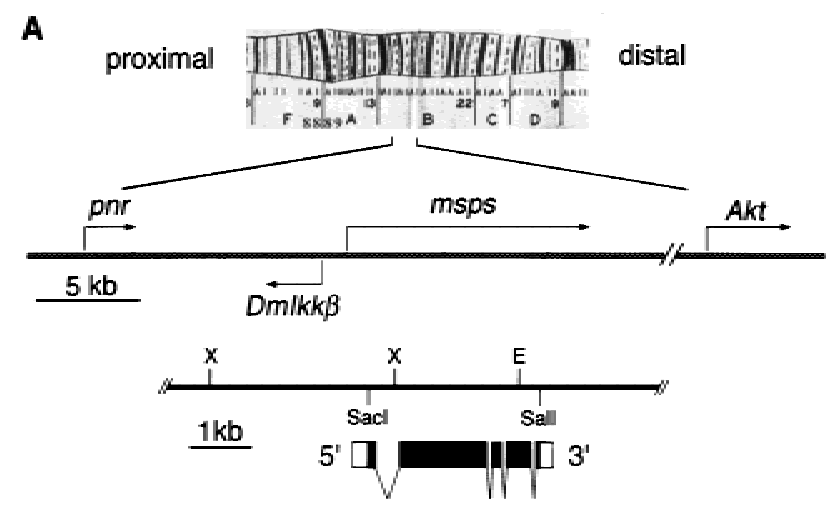

B

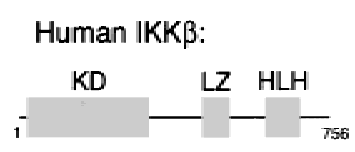

C
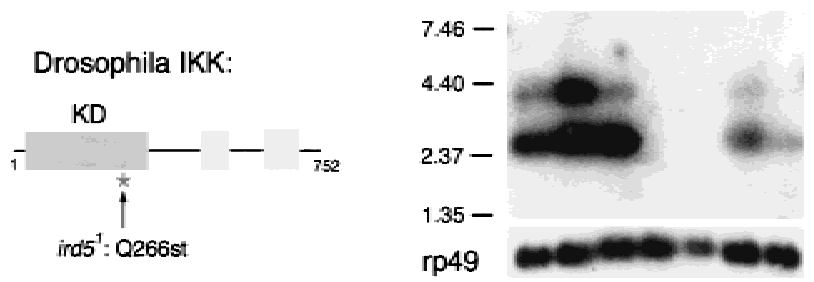

Figure 3. The wild-type $D m I k k \beta$ gene and the ird5 mutations. (A) The $D m I k k \beta$ genomic region in the polytene map. Based on deficiency mapping, ird5 lies in 84B4-9, proximal to $S b$; male recombination mapping placed ird5 distal to pannier (pnr; data not shown). In genomic DNA, DmIkk $\beta$ lies between pnr and mini spindles (msps; Cullen et al. 1999); Akt is $50 \mathrm{~kb}$ distal to $D m I k k \beta$. Comparison of the genomic and cDNA sequences indicated that $D m I k k \beta$ has five exons that produce a $2.7-\mathrm{kb}$ transcript, shown relative to the restriction map of genomic DNA. (B) Comparison of domains of ird5/DmIkk $\beta$ and human IKK $\beta$ indicating the position of the ird $5^{1}$ stop codon. The homology between the Drosophila and human genes is greatest in the kinase domain $(34 \%$ identity to human $I K K \beta)$; there is weak homology to the leucine zipper (LZ) and helix-loop-helix (HLH) motifs in the Drosophila gene (dotted boxes). (C) DmIkk $\beta$ expression in wild-type and ird5 mutants, as assayed by Northern blot. Two transcript sizes, 2.7 and $4.2 \mathrm{~kb}$, are present in wildtype animals; the smaller transcript corresponds to the cDNAs we have isolated. Based on phosphorimager analysis, both $D m I k k \beta$ transcripts are induced 1.5 -fold at $2 \mathrm{~h}$ after infection compared with uninfected animals. $r p 49$ was the loading control. (-), uninfected; (+), 2 h after Escherichia coli infection; L3, third-instar larvae; F, adult female; Df, Df(3R) $s b d^{45}$.

in response to inflammatory signals such as TNF- $\alpha$ and IL-1 (Q. Li et al. 1999; Z. Li et al. 1999); the IKK homolog was therefore considered as a candidate gene for ird5. We cloned a full-length cDNA for the IKK homolog, which we call DmIkk $\beta$ (Fig. 3B). The same gene was also identified molecularly as encoding a kinase activated by LPS in a Drosophila cell line (Kim et al. 2000; Medzhitov and Janeway 2000; Silverman et al. 2000). Based on genomic DNA sequence, $D m I k k \beta$ is located between pannier and mini-spindles (Fig.3A; Experimental Procedures). We de- tected two size classes of transcripts, 2.7 and $4.2 \mathrm{~kb}$, from the DmIkk $\beta$ gene (Fig. 3C); the cDNA corresponded to the 2.7-kb transcript. Both transcripts were expressed at higher levels after infection (Fig. 3C). Similar induction of other genes that encode components of the immune response machinery has been observed previously (Dushay et al. 1996; Lemaitre et al. 1996). We sequenced the complete open reading frame of $D m I k k \beta$ from the ird $5^{1}$ and $i r d 5^{2}$ chromosomes. We identified a single Cto-T nucleotide substitution in $\operatorname{ird} 5^{1}$ that would change a glutamine codon (CAA) at amino acid 266 of the open reading frame to a stop codon (TAA) within the conserved kinase domain (Fig. 3). No sequence changes were identified in the open reading frame in $i r d 5^{2}$; however, neither DmIkk $\beta$ transcript was detectable in ird $5^{2}$ homozygotes (Fig. 3). This analysis indicates that both ird5 alleles are associated with mutations that should abolish DmIkk $\beta$ activity.

To confirm that ird5 is the same as the $D m I k k \beta$ gene, we tested the ability of a $D m I k k \beta$ transgene to rescue the immune response defect of ird5 flies. Neither a UASDmIkk $\beta$ cDNA transgene nor a fat-body GAL4 driver alone rescued the immunity phenotype of ird5 $5^{1}$ (Fig. 4). However, in ird $5^{1}$ diptericin-lacZ/Df(3R)sbd ${ }^{45}$ larvae carrying both a UAS-DmIkk $\beta$ cDNA transgene and a transgene that expressed GAL4 in the fat body, the diptericin-lac $Z$ reporter was activated after $E$. coli infection (Fig. 4). These results demonstrate that $D m I k k \beta$ is the gene responsible for the ird5 mutant phenotype.

\section{Ird5/DmIkk $\beta$ is not a component of the Toll/cactus pathway}

The ird5 immune response phenotype showed striking specificity: All of the antibacterial peptide genes were strongly affected by the ird5 mutations, but the antifungal peptide gene drosomycin was induced normally in ird5 mutants. The specific immune response phenotype of ird5/DmIkk $\beta$ in vivo contrasts with the global effects on antimicrobial peptide genes seen in cell lines when a dominant negative form of the same gene was expressed in cultured cells (Kim et al. 2000). The ird5/DmIkk $\beta$ mutant phenotype implies that, in vivo, ird5 is not an essential component of the Toll pathway, which is required for the induction of drosomycin. The ird5/ $D m I k k \beta$ gene is therefore a component of an independent signaling pathway, which could be activated by another member of the Drosophila Toll-like receptor family (Tauszig et al. 2000).

Mammalian IKK $\alpha$ and IKK $\beta$ phosphorylate serine residues in the N-terminal domain of IкB that target ІкB for degradation, thereby allowing the nuclear localization and activation of NF-кB (Chen et al. 1996; DiDonato et al. 1997; Regnier et al. 1997). The ird5/DmIkk $\beta$ sequence suggests that the protein encoded by this gene phosphorylates an IкB-like protein. There are two known Drosophila IкB-like proteins that could act as inhibitor proteins in the immune response, Cactus, and the Cterminal ankyrin repeat domain of Relish. In cactus mutants, drosomycin is expressed constitutively, but the 


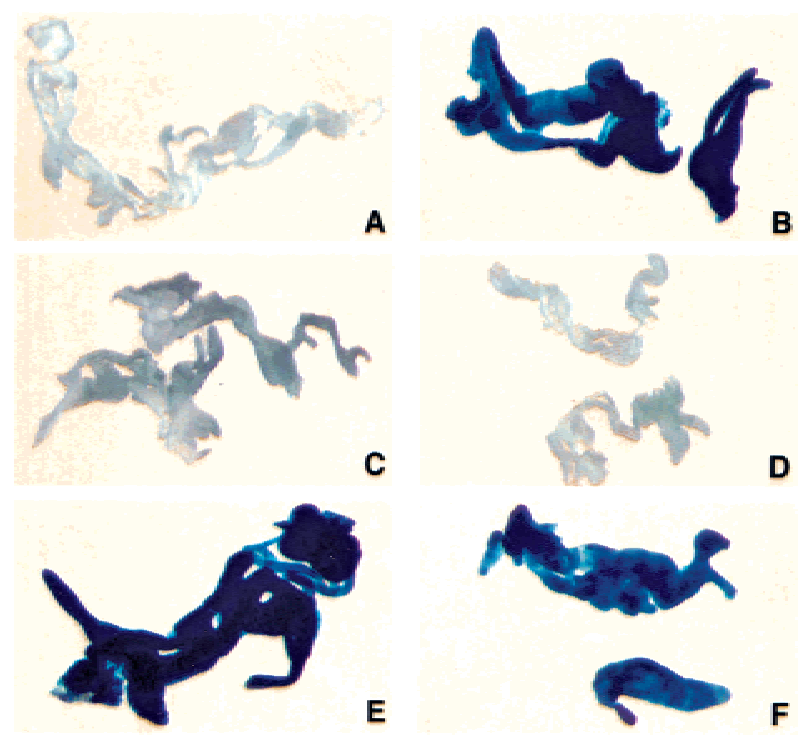

Figure 4. Expression of the DmIkk $\beta$ cDNA rescues the ird5 phenotype. Each panel shows histochemical staining of fat body $\beta$-galactosidase activity in third-instar larvae carrying the diptericin-lac $Z$ reporter gene. Wild-type uninfected $(A)$ and infected $(B)$ larvae, showing the normal induction of the reporter after infection. $(C)$ Fat body from infected w; Gal-c564/+; ird5 ${ }^{1}$, diptericin-lac $Z, e / \mathrm{Df}(3 \mathrm{R}) s b d^{45}$, e larvae. These ird5 animals carrying the GAL4 driver failed to induce the reporter gene, just as do ird5 animals. $(D)$ Fat body from infected $w$; UAS- $D m I k k \beta$ cDNA (6-4)/+; ird $5^{1}$ diptericin-lacZ, e/ ird $5^{1}$ diptericin-lacZ, e larvae. These ird5 animals carrying the UAS-cDNA failed to induce the reporter gene, like ird5 mutants. $(E)$ and $(F)$ ird5 homozygous larvae carrying both the GAL4 driver and the UASDmIkk $\beta$ transgene expressed the reporter gene after infection. (E) Fat body from infected $w$; UAS-DmIkk $\beta$-cDNA (6-4)/Galc564; ird $5^{1}$ diptericin-1acZ, e/Df(3R)sbd $d^{45}$, e larvae. (F) Infected larvae carrying a different transgene insertion site also express the reporter: fat body from infected $w$; UAS-DmIkk $\beta$-cDNA (9-9)/Gal-c564; ird5 ${ }^{1}$ diptericin-lacZ, e/Df(3R)sbd $d^{45}$ animals.

antibacterial peptide genes are not (Lemaitre et al. 1996), which indicates that Cactus is not involved in the pathways that regulate the antibacterial peptide genes. Furthermore, ird5/DmIkk $\beta$ homozygous mutant females are fertile, demonstrating that this gene is not required for degradation of Cactus during dorsal-ventral patterning in the embryo.

\section{Ird5/DmIkk $\beta$ and Relish act in a common pathway}

The ird5/DmIkk $\beta$ phenotype is similar to the phenotype of Relish mutants (Hedengren et al. 1999; Figs. 1,2). For both genes, homozygous mutant flies are viable and fertile, indicating that the two genes are not essential for development. Mutations in either Relish or ird5/ DmIkk $\beta$ completely prevent induction of diptericin and cecropin but allow some induction of attacin and drosomycin (Fig. 1). Mutations in either gene produce comparable effects on bacterial growth (Fig. 2). These results argue that ird5/DmIkk $\beta$ and Relish act in the same sig- naling pathway and suggest that Ird5/DmIkk $\beta$ activates Relish-containing dimers. Relish activation requires proteolytic cleavage of Relish protein into an $\mathrm{N}$-terminal Rel domain that translocates to the nucleus and a Cterminal ankyrin repeat domain that remains in the cytoplasm (Stöven et al. 2000). Recent biochemical experiments have shown that DmIkk $\beta$ can phosphorylate Relish protein (Silverman et al. 2000), which is consistent with the model that phosphorylation of Relish by DmIkk $\beta$ leads to targeted proteolysis and activation of Relish.

Drosophila $І \kappa B$ kinases in development and immunity

Although ird5/DmIkk $\beta$ is expressed maternally (data not shown), ird5 mutant females are fertile, demonstrating that the gene is not required for embryonic dorsalventral patterning. However, a small fraction of embryos $(\sim 0.5 \%)$ produced by homozygous ird $5^{1}$ or ird $5^{1} / \mathrm{ird} 5^{2} \mathrm{fe}-$ males show a weakly dorsalized phenotype (Fig. 5), suggesting that ird5/DmIkk $\beta$ does have a minor role in the maternal pathway that activates Dorsal. We suggest that there is another kinase in the early embryo that is primarily responsible for phosphorylation and degradation of Cactus. The normal induction of drosomycin in ird5/ DmIkk $\beta$ mutants suggests that there will also be another kinase activated by the Toll pathway in the immune response-perhaps the same kinase that acts downstream of Toll to activate Dorsal in the embryo. The genome sequence indicates that there is one additional ІкB kinase gene in Drosophila. Future experiments will test whether this gene plays a role in embryonic patterning and the antifungal immune response.
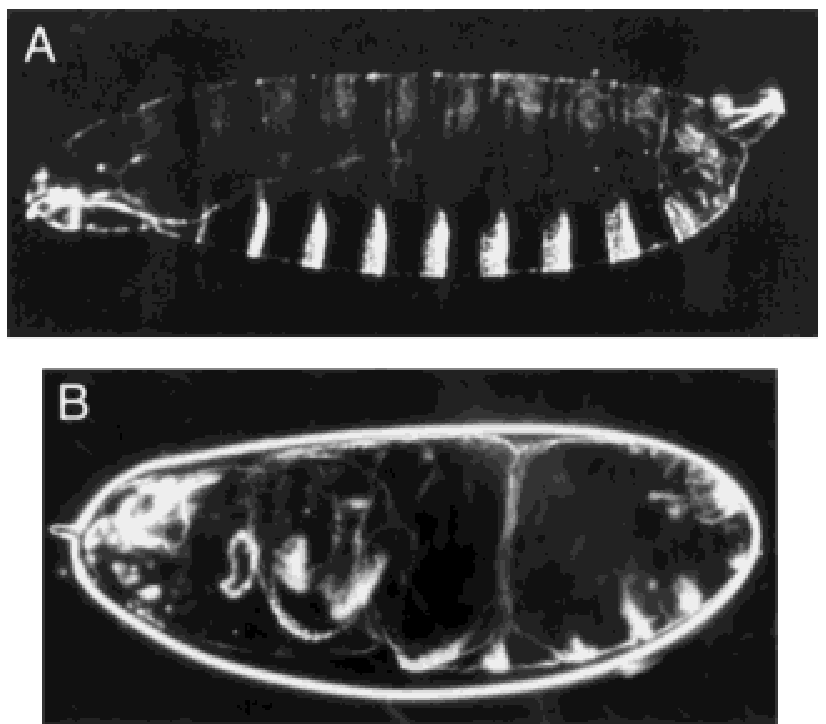

Figure 5. Weak maternal effect of ird5. (A) Dark field view of the cuticle of a wild-type larva just after hatching. Most of the embryos produced by ird5 homozygous females show this wildtype cuticle pattern. Dorsal is up. $(B)$ Cuticle of a weakly dorsalized embryo produced by an ird $5^{1} /$ ird $5^{1}$ female, showing the twisted body characteristic of embryos that have deficiencies in mesoderm, the most ventral cell type (Anderson et al. 1985). 
Our data suggest that different Drosophila Rel dimers are activated by homologous but distinct signaling pathways. Given the similarities of innate immune response pathways in Drosophila and mammals, it is likely that similar pathway-specific signaling components will mediate the activities of the members of the mammalian Rel proteins.

\section{Materials and methods}

\section{Bacterial infection and bacterial survival in infected animals}

In bacterial growth experiments, E. coli were introduced into animals by injection, as described previously (Wu and Anderson 1998). For larvae, E. coli containing an $\mathrm{Amp}^{\mathrm{r}}$ plasmid were diluted 10-fold from an $\mathrm{OD}_{600} 0.5$ culture in PBS and mixed with 1:200-fold diluted India ink. Wandering third instar larvae of the appropriate genotype were injected, with the ink as indicator of the volume injected, transferred to apple juice agar plates, and incubated at $25^{\circ} \mathrm{C}$ for $6-7 \mathrm{~h}$. Because many of the injected larvae pupated shortly thereafter, longer time points were not assayed. For adults, the E. coli culture was diluted 100-fold from an $\mathrm{OD}_{600} 0.5$ culture in PBS; a lower concentration of $E$. coli was used in the adult experiments because adults do not control bacterial growth as efficiently as larvae. Adult flies (1-2 d old) of the appropriate genotype were injected and incubated at $29^{\circ} \mathrm{C}$ for $24 \mathrm{~h}$. For both larvae and adults, three to five animals at the appropriate time after $E$. coli injections were homogenized in LB media and spread on LB plates containing Ampicillin (50 $\mathrm{\mu g}$ / $\mathrm{mL})$.

\section{Molecular characterization of DmIkk $\beta$}

A full-length cDNA corresponding to the 2.7-kb RNA was isolated from an embryonic cDNA library, using the ESTs GM10440 and LD09214 (Genome Systems) as probes. According to the NetStart 1.0 program, the open reading frame is likely to be translated starting at a methionine 20 amino acids upstream of that reported previously (Kim et al. 2000; Medzhitov and Janeway 2000); the position of the stop codon in $i r d 5^{1}$ at position 266 is numbered using this upstream methionine.

We did not isolate cDNAs corresponding to the larger $(4.2-\mathrm{kb})$ RNA, but RT-PCR analysis of RNA from infected larvae revealed that transcripts exist with additional $5^{\prime}$ and $3^{\prime}$ sequences. One transcript has an alternative $3^{\prime}$ coding exon of five amino acids and a different $3^{\prime}$ untranslated region than present in the cDNA.

For sequencing, genomic DNA from wild-type and homozygous ird5 mutant flies was amplified by PCR. Two independent clones of each PCR product were subcloned into pGEM-T vector (Promega) and were sequenced by the Cornell sequencing facility. For Northern analysis of the transcript, RNA was prepared using the RNA-STAT60 (Tel-Test) reagent. Poly(A) ${ }^{+}$RNA was purified using the Oligotex (QIAGEN) kit. Four micrograms of poly $(\mathrm{A})^{+}$RNA was electrophoresed and transferred to Hybond $\mathrm{N}+$ nylon filters.

\section{Northern analysis}

To assay antimicrobial peptide gene induction, E. coli were injected into wandering third-instar larvae and adult flies, as described previously (Wu and Anderson 1998). DNA from the complete DmIkk $\beta$ cDNA and antimicrobial peptide cDNAs were labeled by random priming (Boehringer) and used as probes.

\section{Embryonic phenotypes}

Cuticle preparations were made as described previously (Wieschaus and Nüsslein-Volhard 1986).

\section{Transgene production and rescue of the ird5 phenotype}

The 2.7-kb DmIkk $\beta$ cDNA was cloned into the pUAST $(w+)$ transformation vector (Brand and Perrimon 1993). The construct was introduced into y $W$ flies by $\mathrm{P}$ element-mediated transformation (Spradling 1986). $W^{+}$adults were used to establish several independent lines with insertions located on $\mathrm{X}$, second, and third chromosomes. Several lines with insertions on the second chromosome were crossed with flies carrying ird $5^{1}$ mutant allele to obtain flies with the following genotype: $w$; UAS-DmIkk $\beta$ (cDNA); ird $5^{1}$ diptericin-lacZ, e/T(2;3) CyO; TM6B Tb (strain A). The second-chromosome GAL4 line Galc564, which is expressed in the fat body (Harrison et al. 1995), was used to drive expression of the UAS construct. We confirmed that Gal-c564 is expressed in the fat body by crossing to a UAS-GFP transgenic line. Flies carrying Gal-c564 were crossed to flies carrying a deficiency uncovering ird5 to obtain flies with the following genotype: $w$; Gal-c564; $\mathrm{Df}(3 \mathrm{R}) s b d^{45}, e /$ $\mathrm{T}(2 ; 3) \mathrm{CyO} ; \mathrm{TM} 6 \mathrm{~B} \mathrm{~Tb}$ (strain B). Strains A and B flies were then crossed and the progeny $\mathrm{Tb}^{+}$larvae were selected and tested for the ability to induce the diptericin-lac $Z$ reporter gene in response to infection. Escherichia coli infection and $\beta$-galactosidase activity analysis were performed as described previously (Wu and Anderson 1998), but the staining reaction was carried out for $30-60 \mathrm{~min}$ at $37^{\circ} \mathrm{C}$.

\section{Acknowledgments}

We thank Joe Delaney and David Schneider for help with the design of the bacterial growth experiments. We thank Tim Bestor and Katie Brennan for helpful comments on the manuscript. We thank Pascal Heitzler for deficiency stocks, Armen Manoukian for the Akt allele, Norbert Perrimon for the GAL4 lines (which were generated by K. Kaiser), the Drosophila Stock Centers in Bloomington and Umeå for stocks, and the Berkeley Drosophila Genome Project for EST sequences and cDNA library. This work was supported by NIH AI45149 and the Lita Annenberg Hazen Foundation. L.P.W. is a Leukemia Society of America Special Fellow.

The publication costs of this article were defrayed in part by payment of page charges. This article must therefore be hereby marked "advertisement" in accordance with 18 USC section 1734 solely to indicate this fact.

\section{References}

Anderson, K.V. 2000. Toll signaling pathways in the innate immune response. Curr. Opin. Immunol. 12: 13-19.

Anderson, K.V., Jürgens, G., and Nüsslein-Volhard, C. 1985. Establishment of dorsal-ventral polarity in the Drosophila embryo: Genetic studies on the role of the Toll gene product. Cell 42: 779-789.

Beutler, B. 2000. Tlr4: Central component of the sole mammalian LPS sensor. Curr. Opin. Immunol. 12: 20-26.

Brand, A.H. and Perrimon, N. 1993. Targeted gene expression as a means of altering cell fates and generating dominant phenotypes. Development 118: 401-415.

Chen, Z.J., Parent, L., and Maniatis, T. 1996. Site-specific phosphorylation of I $\mathrm{B} \alpha$ by a novel ubiquitination-dependent protein kinase activity. Cell 84: 853-862. 
Corbo, J.C. and Levine, M. 1996. Characterization of an immunodeficiency mutant in Drosophila. Mech. Dev. 55:211220.

Cullen, C.F., Deak, P., Glover, D.M., and Ohkura, H. 1999. mini spindles: A gene encoding a conserved microtubule-associated protein required for the integrity of the mitotic spindle in Drosophila. J. Cell Biol. 146: 1005-1018.

DiDonato, J.A., Hayakawa, M., Rothwarf, D.M., Zandi, E., and Karin, M. 1997. A cytokine-responsive IкB kinase that activates the transcription factor NF-кB. Nature 388: 548-554.

Dushay, M.S., Asling, B., and Hultmark, D. 1996. Origins of immunity: Relish, a compound Rel-like gene in the antibacterial defense of Drosophila. Proc. Natl. Acad. Sci. 93: 10343-10347.

Elrod-Erickson, M., Mishra, S., and Schneider, D. 2000. Interactions between the cellular and humoral immune responses in Drosophila. Curr. Biol. 10: 781-784.

Harrison, D.A., Binari, R., Nahreini, T.S., Gilman, M., and Perrimon, N. 1995. Activation of a Drosophila Janus kinase (JAK) causes hematopoietic neoplasia and developmental defects. EMBO J. 14: 2857-2865.

Hedengren, M., Asling, B., Dushay, M.S., Ando, I., Ekengren, S., Wihlborg, M., and Hultmark, D. 1999. Relish, a central factor in the control of humoral but not cellular immunity in Drosophila. Mol. Cell 4: 827-837.

Hoffmann, J.A. 1995. Innate immunity of insects. Curr. Opin. Immunol. 7: 4-10.

Hultmark, D. (1993). Immune reactions in Drosophila and other insects: A model for innate immunity. Trends Genet. 9: 178183.

Ip, Y.T., Reach, M., Engström, Y., Kadalayil, L., Cai, H., Gonzalez-Crespo, S., Tatei, K., and Levine, M. 1993. Dif, a dorsalrelated gene that mediates an immune response in Drosophila. Cell 75: 753-763.

Kim, Y.S., Han, S.J., Ryu, J.H., Choi, K.H., Hong, Y.S., Chung, Y.H., Perrot, S., Raibaud, A., Brey, P.T., and Lee, W.J. 2000. Lipopolysaccharide-activated kinase, an essential component for the induction of the antimicrobial peptide genes in Drosophila melanogaster cells. J. Biol. Chem. 275: 20712079.

Lemaitre, B., Kromer-Metzger, E., Michaut, L., Nicolas, E., Meister, M., Georgel, P., Reichhart, J.M., and Hoffmann, J.A. 1995a. A recessive mutation, immune deficiency (imd), defines two distinct control pathways in the Drosophila host defense. Proc. Natl. Acad. Sci. 92: 9465-9469.

Lemaitre, B., Meister, M., Govind, S., Georgel, P., Steward, R., Reichhart, J.M., and Hoffmann, J.A. 1995b. Functional analysis and regulation of nuclear import of Dorsal during the immune response in Drosophila. EMBO J. 14: 536-545.

Lemaitre, B., Nicolas, E., Michaut, L., Reichhart., J.M., Hoffmann, J.A. 1996. The dorsoventral regulatory gene cassette spätzle/Toll/cactus controls the potent antifungal response in Drosophila adults. Cell 86: 973-983.

Lemaitre, B., Reichhart, J.M., and Hoffmann, J.A. 1997. Drosophila host defense: Differential induction of antimicrobial peptide genes after infection by various classes of microorganisms. Proc. Nat1. Acad. Sci. 94: 14614-14619.

Leulier, F., Rodriguez, A., Khush, R.S., Abrams, J.M., and Lemaitre, B. 2000. The Drosophila caspase Dredd is required to resist Gram-negative bacterial infection. EMBO Rep. 1: 353-358.

Levashina, E.A., Ohresser, S., Lemaitre, B., and Imler, J.L. 1998. Two distinct pathways can control expression of the gene encoding the Drosophila antimicrobial peptide metchnikowin. J. Mol. Biol. 278: 515-527.

Li, Q., Van Antwerp, D., Mercurio, F., Lee, K.F., and Verma, I.M.
1999. Severe liver degeneration in mice lacking the IкB kinase 2 gene. Science 284: 321-325.

Li, Z.W., Chu, W., Hu, Y., Delhase, M., Deerinck, T., Ellisman, M., Johnson, R., and Karin, M. 1999. The IKK $\beta$ subunit of IкB kinase (IKK) is essential for nuclear factor $\kappa \mathrm{B}$ activation and prevention of apoptosis. J. Exp. Med. 189: 1839-1845.

Manfruelli, P., Reichhart, J.M., Steward, R., Hoffmann, J.A., and Lemaitre, B. 1999. A mosaic analysis in Drosophila fat body cells of the control of antimicrobial peptide genes by the Rel proteins Dorsal and DIF. EMBO J. 18: 3380-3391.

Medzhitov, R. and Janeway, C. 2000. Innate immune recognition: Mechanisms and pathways. Immun. Rev. 173: 89-97.

Meng, X., Khanuja, B.S., and Ip, Y.T. 1999. Toll receptor-mediated Drosophila immune response requires Dif, an NF-кB factor. Genes \& Dev. 13: 792-797.

Poltorak, A., He, X., Smirnova, I., Liu, M.Y., Huffel, C.V., Du, X., Birdwell, D., Alejos, E., Silva, M.M., Galanos, C., et al. 1998. Defective LPS signaling in $\mathrm{C} 3 \mathrm{H} / \mathrm{HeJ}$ and $\mathrm{C} 57 \mathrm{BL} /$ 10ScCr mice: Mutations in Tlr4 gene. Science 282: 20852088.

Regnier, C.H., Song, H.Y., Gao, X., Goeddel, D.V., Cao, Z., and Rothe, M. 1997. Identification and characterization of an ІкB kinase. Cell 90: 373-383.

Rutschmann, S., Jung, A.C., Hetru, C., Reichhart, J.-M., Hoffmann, J.A., and Ferrandon, D. 2000. The Rel protein DIF mediates the antifungal but not the antibacterial host defense in Drosophila. Immunity 12: 569-580.

Silverman, N., Zhou, R., Stöven, S., Pandey, N., Hultmark, D., and Maniatis, T. 2000. A Drosophila ІкB kinase complex required for Relish cleavage and antibacterial immunity. Genes \& Dev. 14: 2461-2471.

Spradling, A.C. 1986. P element-mediated transformation. In Drosophila: A practical approach (ed. D.M. Roberts), pp. 175-197. IRL, Oxford.

Staveley, B.E., Ruel, L., Jin, J., Stambolic, V., Mastronardi, F.G., Heitzler, P., Woodgett, J.R., and Manoukian, A.S. 1998. Genetic analysis of protein kinase B (AKT) in Drosophila. Curr. Biol. 8: 599-602.

Stöven, S., Ando, I., Kadalayil, L., Engström, Y., and Hultmark, D. 2000. Activation of the Drosophila NF-кB factor Relish by rapid endoproteolytic cleavage. EMBO Rep. 1: 347-352.

Takeuchi, O., Hoshino, K., Kawai, T., Sanjo, H., Takada, H., Ogawa, T., Takeda, K., and Akira, S. 1999. Differential roles of TLR2 and TLR4 in recognition of gram-negative and grampositive bacterial cell wall components. Immunity 11: 443451.

Tauszig, S., Jouanguy, E., Hoffmann, J.A., and Imler, J.L. 2000 Toll-related receptors and the control of antimicrobial peptide expression in Drosophila. Proc. Natl. Acad. Sci. 97: 10520-10525.

Vogel, S.N. 1992. The Lps gene. Insights into the genetic and molecular basis of LPS responsiveness and macrophage differentiation. In Tumor necrosis factors: The molecules and their emerging role in medicine (ed. B. Beutler), pp. 485-513. Raven, New York.

Wieschaus, E. and Nüsslein-Volhard, C. 1986. Looking at embryos. In Drosophila: A practical approach (ed. D.M. Roberts), pp. 199-227. IRL, Oxford.

Williams, M.J., Rodriguez, A., Kimbrell, D.A., and Eldon, E.D. 1997. The 18-wheeler mutation reveals complex antibacterial gene regulation in Drosophila host defense. EMBO $\mathrm{T}$. 16: 6120-6130.

Wu, L.P. and Anderson, K.V. 1998. Regulated nuclear import of Rel proteins in the Drosophila immune response. Nature 392: 93-97. 


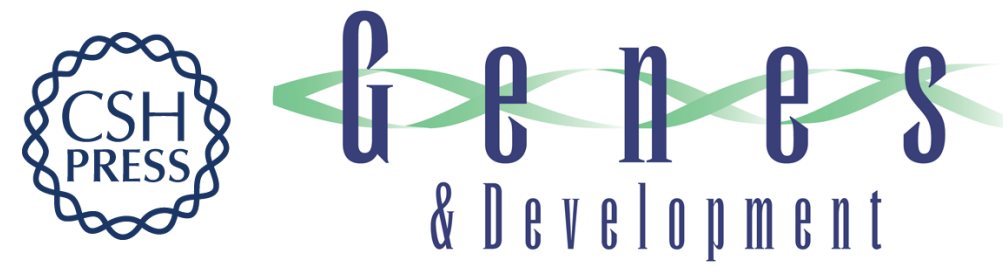

\section{The antibacterial arm of the Drosophila innate immune response requires an I $\kappa B$ kinase}

Yiran Lu, Louisa P. Wu and Kathryn V. Anderson

Genes Dev. 2001, 15:

Access the most recent version at doi:10.1101/gad.856901

References This article cites 36 articles, 15 of which can be accessed free at: http://genesdev.cshlp.org/content/15/1/104.full.htmI\#ref-list-1

License

Email Alerting

Receive free email alerts when new articles cite this article - sign up in the box at the top Service right corner of the article or click here.

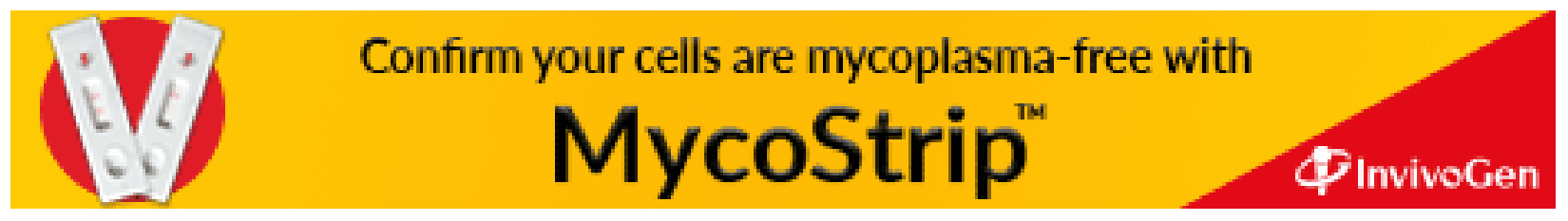

